\title{
Response to modeling and notation of DEA with strong and weak disposable outputs
}

\author{
Jan P. Clement • Vivian G. Valdmanis • \\ Gloria J. Bazzoli • Mei Zhao • Askar Chukmaitov
}

Received: 4 May 2011 / Accepted: 5 May 2011 / Published online: 17 May 2011

(C) Springer Science+Business Media, LLC 2011

Keywords Data Envelopment Analysis (DEA) · Strong, weak disposable outputs

As in the response to modeling and notation of DEA with strong and weak disposable outputs by Gary D. Ferrier, Michael D. Rosko, and Vivian G. Valdmanis, we, too, acknowledge that there were the same errors in our notation in the paper "is more better? An analysis of hospital outcomes and efficiency with a DEA model of output congestion" More specifically, the " $\mu$ " should be on both the weak and strong disposability constraints on outputs [1, 3]. And, as in the case of Ferrier et al., the findings we reported were correct as we used the OnFront software. We thank the authors, L. Kuntz and S. Sülz [2], for identifying the errors in our paper.

\section{References}

1. Clement J, Valdmanis V, Bazzoli G, Zhao M, Chukmaitov A (2008) Is more better? An analysis of hospital outcomes and efficiency with a DEA model of output congestion. Health Care Manage Sci 11(1):67-77

2. Kuntz L, Sülz S, Comment (2011) Modeling and notation of DEA with strong and weak disposable outputs. Health Care Manage Sci 14(4) forthcoming

3. Ferrier GD, Rosko MD, Valdmanis VG (2011) Response to modeling and notation of DEA with strong and weak disposable outputs. Health Care Manage Sci forthcoming
J. P. Clement $(\square) \cdot$ G. J. Bazzoli

Department of Health Administration,

Virginia Commonwealth University,

P.O. Box 980203, Richmond, VA 23298-0203, USA

e-mail: jclement@vcu.edu

G. J. Bazzoli

e-mail: gbazzoli@vcu.edu

\section{G. Valdmanis}

Health Policy Program,

University of the Health Sciences in Philadelphia,

Philadelphia, PA 19104, USA

e-mail: v.valdma@usip.edu
M. Zhao

Health Administration Programs, College of Health,

University of North Florida,

4567 St. Johns Bluff Road, South,

Jacksonville, FL 32224-2673, USA

e-mail: mzhao@unf.edu

\footnotetext{
A. Chukmaitov

Department of Healthcare Policy and Research,

Virginia Commonwealth University,

P.O. Box 980430, Richmond, VA 23298-0430, USA

e-mail: achukmaitov@vcu.edu
} 